\title{
Compreensão de Leitura: Estratégias de Tomar Notas e da Imagem Mental ${ }^{1}$
}

\author{
Sandra Patrícia Ataíde Ferreira \\ Universidade Federal de Pernambuco \\ Maria da Graça Bompastor Borges Dias ${ }^{2}$ \\ Universidade Federal de Pernambuco
}

\begin{abstract}
RESUMO - Objetivou-se verificar e comparar o efeito do treinamento das estratégias de Tomar Notas e da Imagem Mental sobre a compreensão de leitura entre crianças de oito a 14 anos com dificuldades nesta área, de escolas públicas e particulares. Primeiramente, foram classificadas nos Grupos de Pouca e Muita Dificuldade de Compreensão (GD1 e GD2) e distribuídas em três grupos: dois grupos experimentais (GE1 e GE2) e um grupo controle (GC). Depois, o GE1 utilizou a atividade de Tomar Notas e o GE2, a estratégia da Imagem Mental. O GC não recebeu treinamento, mas realizou a mesma tarefa que os grupos experimentais. Os resultados demonstram um desempenho significativamente melhor do GE1 frente ao GE2 e ao GC. Verificou-se que o GD1 progrediu mais sobre as questões inferenciais do que o GD2. As crianças das escolas públicas foram as mais beneficiadas. Ambas estratégias possibilitaram a emergência de respostas às questões literais e inferenciais.
\end{abstract}

Palavras chave: Estratégia de tomar notas; estratégia da imagem mental; compreensão de leitura.

\section{Reading Comprehension: Take Note and Mental Image Activities}

\begin{abstract}
The aim was to verify and compare the effect of strategies at Note-Taking and Mental Image training on reading comprehension among children from eight to 14 years old with difficulty in this area, from public and private schools. Firstly, they were classified in Groups of Little and Much Comprehension Difficulty (DG1 and DG2) and distributed in three groups: two experimental groups (EG1 and EG2) and a control group (CG). Then the EG1 performed the activity of Taking Notes and the EG2, the strategy of the Mental Image. The CG did not receive any training, but accomplished the same task as the experimental groups. The results demonstrate a performance significantly better of the EG1 than EG2 and CG. It was verified that DG1 progressed more on inferential subjects than DG2. Public school children succeeded the most. Both strategies caused the emergency of answers to the inferential and literal subjects.
\end{abstract}

Key words: Note-taking strategy; mental image strategy; reading comprehension.

A leitura é um processo complexo, que implica desvelamento e construção de sentidos. Por envolver os processos de percepção, memória, inferência, dedução, processamento estratégico, a leitura constitui-se como uma atividade cognitiva por excelência. Portanto, como afirmam Oakhill e Garnham (1988), ler é extrair significado, sendo a compreensão o propósito básico da aprendizagem da leitura. Porém, muitas crianças não possuem uma noção precisa sobre o que significa a leitura ou seus objetivos. Assim, Garton e Pratt (1989) sugerem que uma maneira de ajudá-las, é lendo histórias para elas, porque é durante esta atividade que o adulto oferece às mesmas a oportunidade de descobrir as relações entre o significado e as representações gráficas envolvidas em um texto escrito. Além disso, é nessa interação com o adulto, que a criança começa a desenvolver a compreensão de que a leitura é um meio muito importante de realizar objetivos, incluindo desde a obtenção de conhecimentos até à leitura por prazer, por divertimento.

1 Apoio $\mathrm{CNPq}$

2 Endereço: Av. Beira Mar, 520, Apt $^{\circ}$ 81, Piedade - Jaboatão, PE, 54.400010,E-mail: mdias@npd.ufpe.br.
Oakhill e Garnham (1988) também defendem que a compreensão é uma habilidade resultante de uma representação ou modelo mental construído a partir dos assuntos tratados no texto, e afirmam que esta habilidade exige mais do que a capacidade de reconhecer palavras ou de agrupá-las em frase, classes ou sentenças. Outrossim, a construção deste modelo mental envolve uma variedade de habilidades que estão relacionadas tanto a processos de baixo nível (identificação de letras, reconhecimento de palavras, estocagem de informação na memória), como a processos de alto nível (integração de informações e elaboração de inferências), sendo os dois tipos de processamento necessários à atividade de leitura.

A representação que leitores constroem ao compreender um discurso escrito contém tanto informações que estão expressas explicitamente no texto, como informações que não estão no mesmo, mas que podem ser desvendadas do texto ou assumidas a partir de suas bases, sendo esse último tipo de informação chamado de inferência. As inferências que as pessoas fazem ao compreender um texto podem ser abordadas em duas perspectivas: em termos das relações entre os elementos na representação, bem como, em termos da relação da representação para (um modelo de) o mundo. 
Segundo Trabasso e Nicholas (1980), é justamente a possibilidade de encontrar as relações entre as várias partes do texto e entre estas e outros eventos e situações, que o torna significativo, sendo o processo inferencial, portanto, central para a compreensão. Esses autores têm defendido que esta habilidade desenvolve-se no decorrer da idade e que as crianças jovens já são capazes de construir inferências, muito embora não sejam prováveis de usar esta habilidade espontaneamente durante a atividade de decodificação, demonstrando, assim, uma capacidade inferencial incipiente, rudimentar e em desenvolvimento.

Segundo Oakhill e Yuill (1996) e Oakhill, Cain e Yuill (1997), são três as possíveis razões porque maus compreendedores podem falhar para fazer inferências. Primeiro, estes podem simplesmente carecer de conhecimento geral para construir essas inferências. Segundo, eles podem perceber que as inferências são legítimas, mas podem ter dificuldade de acessar o conhecimento relevante e de integrá-lo à informação textual, talvez porque apresentem limitações no processamento de texto. Terceiro, eles podem não perceber que as inferências são necessárias ou permitidas, porque talvez foquem demasiadamente o significado literal do texto.

Apesar de considerarem a relevância do fator conhecimento geral no processo de compreensão, Oakhill e seus colegas percebem a primeira possibilidade de explicação como improvável, já que defendem que as dificuldades nesta área, em muitos casos, estão relacionadas aos processos que estão envolvidos na construção de uma representação de um texto, e não ao conhecimento geral que um indivíduo dispõe.

Oakhill e Garnham (1988) verificaram que a habilidade de compreensão pode ser promovida e que os auxílios à compreensão e os procedimentos de treinamento são prováveis de ser bem sucedidos entre crianças de diferentes idades. Quanto aos auxílios à compreensão, eles têm considerado três principais grupos: 1) uso de adições e mudanças; 2) auxílio ao estudo e; 3) estratégias organizacionais.

As adições e mudanças caracterizam-se pelo uso de figuras, títulos e sumários que são fornecidos ao leitor, sem exigir dele qualquer tipo de esforço ativo.

Os auxilios ao estudo, diferentemente das estratégias citadas anteriormente, exigem uma participação ativa do leitor nas atividades de tomar nota, sublinhar ou escrever sumários, durante ou após a leitura. Têm a desvantagem de não poderem ser realizados por crianças mais jovens, já que requerem habilidades para separar as idéias principais de um texto, como também, a reelaboração de idéias.

As estratégias organizacionais, por sua vez, exigem participação ativa do leitor e podem ser usadas sem auxílios externos, dependendo, apenas, daquilo que é processado na cabeça do indivíduo. Elas podem ser ensinadas a crianças mais jovens e, por serem caracterizadas como estratégias de processamento, podem ser usadas no próprio momento da leitura e aplicadas a qualquer tipo de texto. Como exemplo deste tipo de estratégia, destaca-se a Imagem Mental.

Para o presente estudo foram selecionadas apenas duas estratégias de auxílio à compreensão: a estratégia da Ima- gem Mental, pertencente ao grupo das Estratégias Organizacionais; e a estratégia de Tomar Notas, incluída entre os Auxílios ao Estudo. Dentre as estratégias do grupo Adições e Mudanças, nenhuma foi escolhida. Isto se deu pelo fato destas se diferenciarem das outras duas selecionadas quanto aos requisitos mobilização e envolvimento com a tarefa. Além disso, os estudos já realizados têm demonstrado que as estratégias do grupo Adições e Mudanças apresentam limitações para favorecer o surgimento de habilidades cognitivas mais desenvolvidas, como, aliás, demonstram os resultados de pesquisas já realizadas sobre o uso de figuras, por exemplo (e.g. Lins e Silva, 1994; Spinillo, 1991; Spinillo \& Pinto, 1994).

A imagem mental, que se caracteriza pela tradução de cada sentença do material escrito em imagem durante a leitura, tem-se mostrado como uma eficiente estratégia de auxílio à compreensão de adultos e crianças. Levin (1973), a partir da comparação de dois grupos de crianças, em que um era constituído apenas daquelas com dificuldades de compreensão, mas que possuíam habilidade para decodificar palavras; e o outro, formado de crianças com problemas de decodificação e vocabulário, constatou que a imagem mental beneficiou, apenas, aquelas do primeiro grupo; sugerindo que as instruções de uso de imagem mental melhora com a idade, e que sua eficácia depende do desenvolvimento da habilidade de decodificação. Dias (1995), por sua vez, verificou que crianças em fase de alfabetização também puderam ser beneficiadas pelo uso da imagem mental como estratégia para melhorar o nível de compreensão de histórias que eram lidas para elas.

Em outro estudo, Dias, Morais e Oliveira (1995) verificaram que, além de se mostrar eficiente para possibilitar o progresso no nível de compreensão de leitura de crianças com dificuldades nesta área, o treinamento da estratégia da imagem mental pode ser facilmente administrado, já que não exige nem um longo período de treinamento, nem o uso de recursos onerosos, como filmes ou slides, utilizados nos estudos de Pressley (1976) e Levin (1981). Apresenta-se, pois, como um recurso acessível para remediar tais dificuldades tanto entre alunos de escolas públicas (estaduais e municipais) como entre alunos de escolas particulares.

Oakhill e Patel (1991) também realizaram estudo para verificarem o efeito do treinamento da imagem mental sobre a compreensão de texto entre bons e maus compreendedores com idade média de nove anos e sete meses. Elas concluíram que os maus compreendedores podem beneficiar-se da imagem mental porque este tipo de treinamento pode capacitá-los ou forçá-los a integrar informações no texto, de um modo que eles não podiam fazê-lo. Além disso, segundo as autoras, a imagem mental pode capacitá-los a usar um modo diferente, e talvez mais econômico de representar a informação do texto, ajudando-os a superar as limitações da memória de trabalho.

A outra estratégia investigada, a atividade de tomar notas, que faz parte da categoria de estratégias denominada Auxílio aos Estudos, caracteriza-se, como o próprio nome indica, pela utilização da estratégia de tomar notas sobre as 
idéias que são relevantes no texto, para ajudar a compreensão. Tal atividade oferece ao estudante a oportunidade de reconstruir as idéias do texto a partir de suas próprias palavras, mas, por outro lado, pode levá-lo a reproduzir, de modo fiel, passagens contidas no texto original.

Shimmerlik e Nolan (1976, citado em Oakhill \& Garnham, 1988), depois de pedirem aos sujeitos para tomarem nota dos textos lidos, examinaram a memória para o material escrito realizando testes logo após a leitura e depois de um intervalo de tempo, e constataram que as notas que refletem mudanças na organização do texto são mais eficazes que aquelas que não alteram esta organização, talvez devido ao fato das primeiras exigirem mais esforço e pensamento por parte do leitor, do que as do segundo tipo.

Assim, o propósito deste trabalho foi verificar e comparar a eficácia do treinamento das estratégias de Tomar Notas e da Imagem Mental entre crianças com dificuldade de compreensão. Pretendeu-se comparar o efeito de duas estratégias de natureza similar (ambas exigem a participação ativa do leitor) e de eficiência já comprovada, a fim de se poder apontar as suas prováveis limitações e vantagens enquanto promovedoras da habilidade de compreensão de leitura.

Considerou-se também a relação entre nível de compreensão de leitura em que se encontrava cada criança (muita e pouca dificuldade) e o grau de benefício proposto por cada estratégia utilizada; assim como, a eficácia de cada estratégia para favorecer as respostas das crianças às questões literais e inferenciais.

Vale salientar que, dificuldade de compreensão, neste estudo, deve ser entendida como um déficit que se caracteriza pela incapacidade do leitor para elaborar inferências e para integrar informações no texto, e não unicamente como falta de domínio sobre a decodificação e o vocabulário.

Tendo em vista estes objetivos, este estudo visou responder às seguintes questões: qual das estratégias usadas é mais eficaz para promover a habilidade de compreensão de leitura de crianças com dificuldade nesta área? A eficácia das estratégias varia de acordo com o grau de dificuldade de compreensão apresentado pela criança? As duas estratégias são passíveis de favorecer o surgimento de respostas às questões literais e inferenciais? Qual delas é mais eficiente para fazer gerar elaborações inferenciais e para possibilitar a integração de informações no texto? A partir das respostas a estas perguntas pretendeu-se, também, trazer contribuições para o melhoramento do ensino da leitura e para os procedimentos de treinamento utilizados para remediar dificuldades nesta área.

\section{Método}

\section{Participantes}

Participaram deste estudo 171 crianças de ambos os sexos com idade de 8 a 14 anos, sendo 87 de classes de quarta série do ensino fundamental de duas escolas públicas estaduais e 84 de classes de terceira série do ensino fundamental de três escolas particulares, da cidade do Recife. As crianças do primeiro tipo de escola tinham entre 9 e 14 anos, e as do segundo tipo, de 8 a 10 anos. Todos os participantes de cada tipo de escola foram avaliados, em um primeiro momento, através de tarefa de leitura e compreensão de textos e classificados, posteriormente, em dois níveis de dificuldade de compreensão (muita e pouca dificuldade), de acordo com o desempenho obtido naquela tarefa.

Desse total geral, foram selecionadas 30 crianças de cada tipo de escola, sendo 15 classificadas no nível de muita dificuldade de compreensão e 15 no nível de pouca dificuldade, as quais foram distribuídas em três grupos de 10 participantes (dois grupos experimentais e um grupo controle), ficando 5 participantes, de cada grupo de 10, em um dos dois níveis de dificuldade de compreensão, perfazendo um total geral de 60 participantes.

A distinção entre as séries das crianças dos dois tipos de estabelecimento escolar, está baseada na constatação de "que as crianças da rede pública, na cidade do Recife, iniciam o processo de alfabetização na primeira série, ao contrário das crianças da rede particular, que iniciam este processo na sala de alfabetização, que é anterior a primeira série do primeiro grau" (Lins \& Silva, 1994, p. 34). Implicando, portanto, em diferenças quanto à variável tempo de escolaridade, que foi controlada neste estudo.

O exame ou controle da memória não foi considerado neste estudo, apesar de se reconhecer a relevância da memória no processo de compreensão de textos. Isto em virtude do objetivo deste trabalho não ter sido investigar os processos envolvidos na habilidade de compreensão de textos ou a maior ou menor participação de cada um deles na determinação desta capacidade ou de suas deficiências; mas, verificar a eficácia das estratégias de Tomar Notas e da Imagem Mental como auxílio à compreensão de crianças com dificuldade nesta área e oriundas de contextos escolares distintos.

\section{Material}

Para a tarefa de classificação dos participantes, foi utilizado um conjunto de três histórias acompanhadas de seis questões cada uma, sendo as três primeiras consideradas literais e as três últimas, inferenciais (Anexo A). Já para a atividade de treinamento dos participantes para o uso das estratégias de tomar notas e da imagem mental, foi usada uma narrativa adicional com nove questões respectivas (Anexo B) das quais, as três primeiras foram tratadas como literais e as demais, como inferenciais.

Quanto ao treinamento para o uso da estratégia de tomar notas, utilizaram-se, também, folhas de papel tamanho ofício para que os participantes tomassem notas de informações existentes no texto que foi lido. Usou-se, ainda, um gravador para o registro das sessões de entrevista com cada criança.

As quatro histórias utilizadas neste estudo não eram inéditas, tendo sido a eficácia de sua aplicabilidade à faixa etária aqui considerada já comprovada em experimentos anteriores (Brandão, 1994; Dias \& cols., 1995). 
Às questões utilizadas, como já foi mencionado, foram considerados dois tipos de pergunta:

- Perguntas Literais, as quais envolvem a identificação e reprodução de informações contidas no texto, sem exigir qualquer tipo de envolvimento do leitor com o significado que pode ser gerado a partir da sua interação com o texto;

- Perguntas Inferenciais, que são aquelas que recorrem à integração de informações no próprio texto e à relação dessas informações com o conhecimento de mundo do leitor, possibilitando-o atribuir sentido ao texto lido, já que exige dele o trabalho de relacionar todas essas informações.

\section{Procedimentos}

\section{Primeira Fase (Situação de Pré-teste): Classificação dos participantes nos dois niveis de dificuldade de compreensão de leitura.}

Todos os participantes das escolas estaduais e particulares foram testados individualmente através do conjunto das três histórias utilizadas neste experimento. Inicialmente, nesta situação de pré-teste, pediu-se aos participantes que lessem uma narrativa do livro que estava sendo usado em sala de aula e que, em seguida, respondessem a quatro questões de sondagem que já tinham sido usadas no estudo de Dias e colaboradores (1995). Isto em virtude destas autoras terem verificado que "muitas crianças mostraram-se hesitantes e relutantes na realização da tarefa de leitura da história inicial" (p. 9), não sendo o mesmo observado nas tarefas subseqüentes. Este procedimento também foi importante para excluir da amostra as crianças que não tinham domínio sobre a decodificação.

Seguindo-se a esta atividade inicial, apresentava-se ao participante a primeira história do experimento, que era lida em voz alta. A criança também foi esclarecida sobre o fato de que não poderia consultar a história enquanto respondesse às questões que lhe seriam feitas após a atividade de leitura. Todas as questões foram colocadas e respondidas oralmente.

Os participantes, nesta primeira fase, como no estudo de Dias e colaboradores (1995), foram classificados quanto ao nível de dificuldade de compreensão de leitura com base no desempenho exibido por eles frente a cada história. Aqueles que conseguiram ler, mas não foram capazes de responder corretamente todas as questões de compreensão sobre a primeira história, foram classificados no nível de muita dificuldade de compreensão; os que leram a primeira e segunda história, mas não foram capazes de responder as questões desta última, foram classificados no nível de média dificuldade de compreensão e; aqueles que conseguiram ler todas as três histórias, mas que não foram capazes de responder às questões de compreensão referentes à última história, foram classificados no nível de pouca dificuldade de compreensão. Para este estudo, foram consideradas, apenas, as crianças classificadas nos níveis de muita e pouca dificuldade.
No final desta primeira fase, as crianças foram distribuídas aleatoriamente nos dois Grupos Experimentais (GEl e $G E 2)$ e no Grupo Controle (GC), sendo cada um desses grupos composto por crianças dos dois níveis de dificuldade de compreensão.

\section{Segunda Fase (Situação de Pós-teste): Manipulação das estratégias de auxílio à compreensão: atividades de tomar notas e da imagem mental.}

Esta fase, que teve caráter de pós-teste, ocorreu uma semana depois. Os participantes dos dois grupos experimentais e do grupo controle, que foram classificados no nível de muita dificuldade de compreensão receberam a primeira história, cujas questões não conseguiram responder corretamente na primeira fase, e foram instruídos no sentido de ler a história novamente em voz alta, esforçando-se para compreender a história, já que, após a leitura, os mesmos eram solicitados a responder às questões referentes àquela história. Por outro lado, aqueles que foram classificados no nível de pouca dificuldade de compreensão, receberam a terceira história, recebendo as mesmas orientações.

As crianças do GE1 foram submetidas ao treinamento da estratégia de Tomar Notas e as do GE2 ao da Imagem Mental, durante uma única sessão. Aquelas pertencentes ao grupo controle (GC), não receberam tal treinamento, mas foram instruídas a ler e a responder às questões de compreensão da história que leram na primeira fase do estudo, uma semana após a primeira fase. Com esta segunda avaliação, foi possível comparar o nível de dificuldade de compreensão dos participantes deste grupo com o nível de dificuldade de compreensão daqueles que participaram dos dois grupos experimentais; como também, comparar estes resultados com aqueles obtidos na primeira fase do experimento, para verificar se houve ou não avanço no nível de compreensão dos participantes do grupo controle.

\section{Treinamento para o uso da Estratégia de Tomar Notas}

Todos os participantes deste grupo (GE 1) foram instruídos a tomar notas das passagens da história que para eles pareciam mais importantes, e foram alertados de que esta é uma boa maneira de se obter compreensão de narrativas. Neste treinamento, as crianças foram orientadas a fazer anotações com suas próprias palavras e a evitar transcrição literal das sentenças da história.

No entanto, como não se podia pressupor que as crianças das séries estudadas, já tivessem adquirido habilidade metatextual, ou seja, a capacidade para pensar sobre a estrutura da narrativa e suas características específicas, foi proposta a elas uma tarefa com a finalidade de levá-las a refletir sobre aquela e sobre suas passagens relevantes.

Para tal, foi utilizado uma história adicional (Anexo B), usada especialmente para o treinamento. Para facilitar a compreensão, a experimentadora pedia para que a criança, primeiramente, separasse as palavras principais do parágrafo que acabara de ler, para, por fim, construir uma frase com 
aquelas palavras previamente selecionadas. A criança era também orientada a preservar o assunto abordado em cada parágrafo e a evitar distorções das informações oferecidas pela história.

Após a leitura e discussão de toda a história, a experimentadora pedia para que a criança falasse sobre ela, a fim de verificar a sua compreensão, observando, principalmente, a sua capacidade para elaborar inferências verdadeiras, isto é, para construir uma representação de significado condizente com o texto original.

Depois deste treinamento, a experimentadora entregava ao sujeito a história que o mesmo não foi capaz de responder às perguntas de compreensão, na primeira fase, dizendo-lhe para lê-la cuidadosamente e para tomar notas das passagens principais de cada parágrafo.

\section{Treinamento para o uso da Estratégia da Imagem Mental}

No grupo experimental II (imagem mental), as crianças, assim como no estudo de Dias e colaboradores (1995), foram orientadas a fazer "desenhos na cabeça" de cada sentença lida, e foram instruídas a pensar que esta é uma boa maneira de se lembrar de histórias lidas.

Contudo, antes de se iniciar as atividades de leitura, era proposta à criança uma atividade lúdica que envolvia a capacidade de elaborar imagens mentais a respeito de uma situação que era verbalmente descrita pela investigadora.

Depois dessa atividade preliminar, a experimentadora entregava a história adicional ao participante, pedindo-lhe para ler em voz alta e para criar imagens mentais do conteúdo da mesma. Quando a criança terminava de fazer a leitura, a experimentadora pedia a ela para descrever, uma a uma, as imagens que ela elaborou sobre a narrativa. Depois disto, a mesma recebia a história cujas questões não foi capaz de responder na primeira fase, sendo instruída a ler com cuidado para, a seguir, falar das imagens mentais que tinha sido capaz de construir e responder às questões de compreensão.

No final da entrevista, a experimentadora perguntava qual o procedimento usado para lembrar do conteúdo da história. Esta pergunta era feita com o objetivo de se saber se a criança tinha feito ou não o uso da imagem mental, durante a leitura.

Todas as entrevistas realizadas com os participantes, na primeira e segunda fase, foram gravadas em áudio e, posteriormente, transcritas.

\section{Resultados}

Para a análise quantitativa dos dados, recorreu-se aos testes estatísticos $U$ de Mann-Whitney e dos Sinais. Esta escolha baseou-se, especialmente, no fato de ambos os testes serem não-paramêtricos e, portanto, adequados para a análise de amostras não homogêneas, como a amostra em questão. O U de Mann-Whitney foi escolhido por permitir a análise de amostras independentes (análise intergrupo) e o dos Sinais, por ser adequado para a análise de amostras relacionadas (análise intragrupo).
Tabela 1. Médias de Respostas Corretas, por Tipo de Questão, apresentadas pelos Grupos Experimentais e Controle de toda a Amostra, nas duas Fases do Estudo

\begin{tabular}{lrrrr}
\hline \multirow{2}{*}{ Grupo } & \multicolumn{2}{c}{ Questões Literais } & \multicolumn{2}{c}{ Questões Inferenciais } \\
\cline { 2 - 5 } & Pré-teste & Pós-teste & Pré-teste & \multicolumn{1}{c}{ Pós-teste } \\
\hline GE1 & 2,35 & 2,70 & 1,60 & 2,35 \\
\hline GE2 & 2,30 & 2,60 & 2,05 & 2,25 \\
\hline GC & 2,65 & 2,85 & 1,65 & 1,90 \\
\hline
\end{tabular}

GE1 = Tomar Notas; GE2 = Imagem Mental; GC = Controle

\section{Treinamento X Grupos Experimentais e Controle}

A comparação entre os resultados observados nas duas fases do estudo apontou para um progresso geral no desempenho dos dois Grupos Experimentais e do Grupo Controle (ver Tabela 1).

O teste estatístico evidenciou uma diferença significativa entre o desempenho do GE1 e do GC sobre as questões inferenciais $(U=126 ; p=0,02)$, na segunda fase do estudo, observando-se uma superioridade do primeiro sobre o segundo grupo, nesta tarefa. No entanto, ao se confrontar o desempenho demonstrado pelo GE2 e o GC $(U=142 ; p=$ $0,06)$, assim como, pelo GE1 e o GE2 $(U=182 ; p=0,58)$ sobre as questões inferenciais, nenhuma diferença significativa foi encontrada, em quaisquer dos dois momentos do estudo. A ausência de diferenças significativas entre os grupos também foi confirmada quando se comparou a performance dos mesmos (GE1/GC, GE2/GC e GE1/GE2) sobre as questões literais, no pré-teste e no pós-teste.

As diferenças intragrupos foram verificadas pelo Teste dos Sinais, que evidenciou como sendo significativas as diferenças de desempenho exibidas pelo GE1 sobre as questões literais $(p=0,007)$ e inferenciais $(p=0,005)$, de um momento para o outro do estudo. Todavia, não foram encontradas diferenças significativas para o GE2 (QL; $p=0,06$; QI.; $p=0,1)$ e o GC (QL.; $p=0,1 ; \mathrm{QI} . ; p=0,8)$, do momento do pré-teste para o pós-teste, para qualquer uma dessas categorias. Essas diferenças significativas encontradas através da análise intragrupo parecem demonstrar um progresso expressivo do GE1 no segundo momento da atividade de compreensão de leitura, sugerindo um possível efeito da estratégia de Tomar Notas sobre este tipo de habilidade.

O conjunto desses resultados parece apontar, ainda, para um maior poder de eficácia da estratégia de Tomar Notas para possibilitar a promoção da habilidade de compreensão entre crianças quando comparada a da Imagem Mental.

\section{Treinamento X Grupos de Dificuldade de Compreensão}

A comparação entre o desempenho apresentado pelos grupos de dificuldade de compreensão de leitura (GD1 e GD2) sobre as questões literais e inferenciais, do momento do pré-teste para o pós-teste, revela diferenças intragrupos que foram verificadas pelo Teste dos Sinais e apontadas como sendo significativas (unilaterais) para o GD1 sobre as questões literais $(p=0,001)$ e para o GD2 sobre as questões inferenciais $(p=0,0001)$. (ver Tabela 2$)$ 
Tabela 2. Médias de Respostas Corretas, por tipo de questão, apresentadas pelos grupos de dificuldade de compreensão, nas duas fases do estudo.

\begin{tabular}{lcccc}
\hline \multirow{2}{*}{ Grupo } & \multicolumn{2}{c}{ Questões Literais } & \multicolumn{2}{c}{ Questões Inferenciais } \\
\cline { 2 - 5 } & Pré-teste & Pós-teste & Pré-teste & Pós-teste \\
\hline GD1 & 2,50 & 2,80 & 1,86 & 2,03 \\
\hline GD2 & 2,36 & 2,63 & 1,66 & 2,30 \\
\hline
\end{tabular}

GD1 = Muita dificuldade de compreensão

GD2 = Pouca dificuldade de compreensão

Os resultados apresentados pelos Grupos Experimentais e Controle pertencentes ao grupo de crianças com Muita Dificuldade (GD1) foram analisados pelo Teste $U$ de MannWhitney, que apontou como sendo significativas as diferenças de desempenho apresentadas pelo GE1 e o GE2 ( $U=30$; $p=0,05)$ sobre as questões literais, no segundo momento do estudo, demonstrando-se uma supremacia do GE1 sobre o GE2. Verificam-se, ainda, diferenças significativas entre o GE2 e o GC ( $U=25 ; p=0,01)$ sobre as questões literais, no segundo momento do estudo, revelando-se, desta vez, uma superioridade do GC sobre o GE2. Nenhuma outra diferença significativa foi encontrada. (ver Tabela 3)

No que se refere ao Grupo de Pouca Dificuldade de Compreensão (GD2), o Teste $U$ de Mann-Whitney demonstrou como sendo significativas as diferenças apresentadas entre a performance do GE1 e o GC sobre as questões literais $(U=$ $23,5 ; p=0,023)$, na primeira fase do estudo, com vantagem para o segundo grupo; e sobre as questões inferenciais $(U=$ $20 ; p=0,014)$, no pós-teste, constatando-se, desta vez, uma superioridade do GE1 sobre o GC. Também foram encontradas diferenças significativas entre o GE2 e o GC sobre as questões inferenciais, na segunda fase do estudo, com vantagem para o GE2. Nenhuma outra diferença significativa foi encontrada. (ver Tabela 3)

No que se refere às diferenças intragrupos apresentadas pelos grupos experimentais e controle originários do Grupo de Muita Dificuldade de Compreensão, o Teste dos Sinais não verificou nenhuma diferença significativa (unilateral) nem para o GE1 (QL; $p=0,125 ; \mathrm{QI} ; p=0,25)$ e GE2 (QL; $p$ $=0,25 ; \mathrm{QI} ; p=0,5)$ nem para o $\mathrm{GC}(\mathrm{QL} ; p=0,062$; $\mathrm{QI} ; p=$
Tabela 4. Médias de Respostas Corretas, por tipo de questão, apresentadas pelas populações dos dois tipos de escola, nas duas fases do estudo.

\begin{tabular}{lcccc}
\hline \multirow{2}{*}{ Tipo de Escola } & \multicolumn{2}{c}{ Questões Literais } & \multicolumn{2}{c}{ Questões Inferenciais } \\
\cline { 2 - 5 } & Pré-teste & Pós-teste & Pré-teste & Pós-teste \\
\hline Estadual & 2,56 & 2,70 & 1,70 & 2,06 \\
\hline Particular & 2,30 & 2,73 & 1,83 & 2,26 \\
\hline
\end{tabular}

0,5), de um momento para o outro do estudo, para qualquer uma das categorias de resposta.

Quanto aos grupos experimentais e controle, pertencentes ao Grupo de Pouca Dificuldade de Compreensão, o Teste dos Sinais apontou como sendo significativas as diferenças (unilaterais) apresentadas pelo desempenho do GE1 sobre as questões inferenciais $(p=0,019)$, de um momento para o outro do estudo. Nenhuma outra diferença significativa foi encontrada. Este tipo de resultado parece indicar que a estratégia de Tomar Notas pode ser mais bem aproveitada por crianças que demonstram menos dificuldade de compreensão, do que por aquelas que apresentam mais dificuldade.

\section{Treinamento X Tipo de Escola}

O teste $U$ de Mann-Whitney não verificou diferença significativa entre os dois tipos escola (pública e particular) quanto ao desempenho demonstrado pelas crianças sobre as questões literais e inferenciais.

As diferenças intragrupos foram constatadas pelo Teste de Sinais, que apontou como sendo significativas (unilaterais) as diferenças de desempenho apresentadas pela amostra da escola estadual sobre as questões inferenciais $(p=$ $0,01)$ e pela amostra da escola particular sobre as questões literais $(p=0,0001)$, do momento do pré-teste para o pósteste.

Para verificar estatisticamente as diferenças entre os grupos experimentais e controle, originários da escola pública, foi utilizado o Teste $U$ de Mann-Whitney, que apontou como

Tabela 3. Médias de Respostas Corretas, por tipo de questão, apresentadas pelos Grupos Experimentais e Controle pertencentes aos dois Grupos de Dificuldade de Compreensão, nos dois momentos do estudo.

\begin{tabular}{lccccccc}
\hline \multirow{2}{*}{$\begin{array}{c}\text { Grupos de } \\
\text { Dificuldade }\end{array}$} & $\begin{array}{c}\text { Número de } \\
\text { Casos }\end{array}$ & & \multicolumn{5}{c}{ Questões Literais } \\
\cline { 3 - 8 } & & GE1 & GE2 & GC & GE1 & GE2 & GC \\
\hline GD1 & 30 & 2,60 & 2,30 & 2,60 & 2,90 & 2,50 & 3,00 \\
\hline GD2 & 30 & 2,10 & 2,30 & 2,70 & 2,50 & 2,70 & 2,70 \\
\hline & & & Questões Inferenciais & Geste \\
\hline GD1 & 30 & GE1 & GE2 & GC & GE1 & GE2 & GC \\
\hline GD2 & 1,70 & 2,10 & 1,80 & 2,10 & 2,00 & 2,00 \\
\hline
\end{tabular}

GD1 = Muita Dificuldade; GD2 = Pouca Dificuldade; GE1 = Tomar Notas; GE2 = Imagem Mental; GC = Controle 
Tabela 5. Médias de Respostas Corretas, por tipo de questão, apresentadas pelos Grupos Experimentais e Controle pertencentes aos dois tipos de escola, nos dois momentos do estudo.

\begin{tabular}{|c|c|c|c|c|c|c|c|}
\hline \multirow{3}{*}{ Tipo de Escola } & \multirow{3}{*}{$\begin{array}{l}\text { Número de } \\
\text { Casos }\end{array}$} & \multicolumn{6}{|c|}{ Questões Literais } \\
\hline & & \multicolumn{3}{|c|}{ Pré-teste } & \multicolumn{3}{|c|}{ Pós-teste } \\
\hline & & GE1 & GE2 & GC & GE1 & GE2 & GC \\
\hline Estadual & 30 & 2,30 & 2,60 & 2,80 & 2,60 & 2,70 & 2,80 \\
\hline \multirow[t]{3}{*}{ Particular } & 30 & 2,40 & 2,00 & 2,50 & 2,80 & 2,50 & 2,90 \\
\hline & & \multicolumn{6}{|c|}{ Questões Inferenciais } \\
\hline & & GE1 & GE2 & GC & GE1 & GE2 & GC \\
\hline Estadual & 30 & 1,40 & 2,00 & 1,70 & 2,20 & 2,20 & 1,80 \\
\hline Particular & 30 & 1,80 & 2,10 & 1,60 & 2,50 & 2,30 & 2,00 \\
\hline
\end{tabular}

GE1 = Tomar Notas; GE2 = Imagem Mental; GC = Controle

significativas as diferenças entre o GE2 e o GC $(U=32 ; p=$ $0,051)$ sobre as questões inferenciais, na segunda fase do estudo, observando-se uma superioridade do primeiro sobre o segundo grupo. Porém, nenhuma outra diferença significativa foi encontrada entre os grupos experimentais e controle pertencentes a este tipo de escola. (ver Tabela 5)

Quanto à escola particular, o teste $U$ de Mann-Whitney revelou uma diferença significativa $(U=30 ; p=0,05)$ entre os grupos GE2 (Imagem Mental) e o GC (Controle) sobre as questões literais, do momento do pré-teste para o pós-teste, com vantagem para o último grupo. Nenhuma outra diferença significativa foi encontrada. (ver Tabela 5)

Esses resultados parecem indicar que o treinamento para o uso da Imagem Mental foi mais bem aproveitado pelas crianças da escola pública quando comparadas as da escola particular.

Os resultados intragrupos apresentados pelos grupos experimentais e controle da escola pública foram analisados pelo Teste dos Sinais, que apontou como significativas (unilaterais) as diferenças de desempenho demonstradas pelo GE1 (Tomar Notas) sobre as questões inferenciais $(p=$ 0,031), de um momento para o outro do estudo. Entretanto, não foram encontradas diferenças significativas entre as performances do GE2 (Imagem Mental) e do GC (Controle) em relação a si mesmos, do momento do pré-teste para o pós-teste.

No que diz respeito aos grupos experimentais e controle, originários da população da escola particular, o teste dos Sinais não verificou nenhuma diferença significativa entre o desempenho intragrupo exibido pelo GE1 e o GE2 nem pelo GC, do momento do pré-teste para o pós-teste, para nenhuma das duas categorias de resposta.

As diferenças significativas encontradas para os grupos experimentais e controle de cada tipo de escola parecem indicar que, embora a estratégia da Imagem Mental tenha se mostrado mais efetiva para favorecer a compreensão das crianças oriundas da escola pública quando comparadas às da escola particular, a estratégia de Tomar Notas mostrou-se mais eficaz do que a da Imagem Mental para promover a habilidade de compreensão entre as crianças do primeiro tipo de escola que foram instruídas a utilizá-las.

\section{Discussão e Conclusões}

Investigar e comparar a eficácia das estratégias de Tomar Notas e da Imagem Mental como auxílio à compreensão de textos de crianças com dificuldades nesta área, foi a proposta deste trabalho, que também visou apontar novas perspectivas que possam contribuir para o desenvolvimento do Ensino da Leitura enquanto uma atividade crítica, criativa e significativa.

De um modo geral, apesar de se ter identificado diferenças quanto ao grau de eficácia revelado pelas estratégias de Tomar Notas e da Imagem Mental, pode-se concluir que ambas as estratégias são eficientes para possibilitar a reconstrução do significado do texto a partir da integração de informações e da construção de inferências, sendo, conseqüentemente, prováveis de promover a capacidade de compreensão de crianças com dificuldade nesta área. Como foi observado no presente estudo, aquelas crianças que participaram do treinamento para o uso das estratégias aqui utilizadas obtiveram mais êxito na tarefa de compreensão proposta do que aquelas que dele não participaram. Passemos, então, à discussão e conclusão sobre cada variável estudada.

\section{Treinamento X Grupos de Dificuldade de Compreensão}

Quando se observa o efeito do treinamento para o uso das estratégias de Tomar Notas e da Imagem Mental sobre os Grupos de Dificuldade de Compreensão (GD1 = muita dificuldade e GD2 = pouca dificuldade), percebe-se que as crianças classificadas no GD2 foram as que mais se beneficiaram, apresentando melhor desempenho sobre as questões inferenciais, após o treinamento, fazendo-se supor que o grau de eficácia das estratégias varia de acordo com a dificuldade de compreensão apresentada pela criança.

Diante desses resultados, é possível pensar que as crianças classificadas no GD2 são mais capazes de apreender e lidar com informações novas, sendo mais prováveis de abandonarem as antigas estratégias de apelo à memória em favor de estratégias que recorrem ao sentido, em um período mais curto de tempo, a partir de um uso mais efetivo da estratégia ensinada. Deste modo, estas crianças mostraram-se mais 
aptas para integrar as várias informações disponíveis, transformando a informação explícita em informação significativa, e, portanto mais acessível à memória de longo prazo. Além disso, verifica-se, quando se observam as diferenças significativas obtidas a partir da análise dos grupos experimentais e controle, originários do GD2, que as crianças classificadas neste grupo foram mais beneficiadas pelo treinamento para o uso da estratégia de Tomar Notas, do que pelo da Imagem Mental.

Em contrapartida, as crianças classificadas no GD1 parecem usar a nova estratégia mais como um meio de assegurar a memorização da informação explícita no texto, de forma literal, demonstrando pouca habilidade para integrar as várias informações nele contidas e, especialmente, para integrar estas informações ao seu conhecimento de mundo.

Vale salientar, no entanto, que este tipo dificuldade não foi exclusiva para o GD1, podendo ser identificada na maioria das crianças investigadas. No entanto, aquelas classificadas no GD2 tiveram mais êxito em superá-la, após a instrução para o uso das estratégias de Tomar Notas ou Imagem Mental, do que aquelas pertencentes ao primeiro grupo.

Diante disto, três hipóteses são consideradas: ou as crianças da amostra estudada são incapazes de ativar o conhecimento de mundo, durante a leitura; ou não possuem consciência da relevância deste conhecimento enquanto elemento essencial à compreensão de textos ou esta habilidade para utilizar informações múltiplas de maneira eficiente desenvolve-se mais tardiamente, sendo impulsionada pela mediação adulto-texto-criança. Se considerarmos esta última hipótese como a mais provável, então, os resultados aqui encontrados confirmam, por uma parte, os achados de Terzi (1995) que, ao investigar o desenvolvimento do processo de leitura de três crianças de meios iletrados, verificou que as mesmas só passaram a integrar as informações textuais com seu conhecimento prévio em um estágio mais avançado deste desenvolvimento, quando já eram capazes de perceber o texto como produção de um autor distante e não mais como uma propriedade do leitor.

De acordo com Terzi, esta não-consideração da existência do autor pode ser justificada, em parte, à pouca exposição daquelas crianças à leitura de livros, pois como ressalta esta autora, a aprendizagem da concepção de leitura enquanto interação autor-leitor via texto tem início, no mundo dos letrados, nas situações de leitura mediadas pelo adulto, que durante esta atividade, expõe a criança a eventos distantes do seu contexto imediato, levando-a a estabelecer conexões entre o mundo descrito pelo autor e o seu próprio mundo.

Neste aspecto, pode-se dizer que os nossos resultados confirmam esta hipótese mais precisamente no que se refere à amostra constituída pelas crianças da escola pública estadual, que, em geral, pertencem a comunidades sócio-economicamente menos favorecidas e, supostamente, com menos acesso ao mundo da escrita do que aquelas crianças de escola particular, que se supõe pertencerem a um nível sócioeconômico mais privilegiado e, hipoteticamente, com mais possibilidades de acesso ao letramento.
Mas o que dizer das crianças que constituíram a outra metade da amostra do presente estudo e que são oriundas de meios letrados? Será que estas também adquirem a habilidade de integrar o conhecimento prévio às informações textuais em um estágio mais avançado do desenvolvimento? Nossos resultados evidenciam que a dificuldade para integrar estes dois níveis de conhecimento está presente também entre estas crianças.

Isto leva a crer que a capacidade para integrar o conhecimento prévio às informações textuais configura-se como uma habilidade sofisticada e, por isso, conquistada mais tardiamente no processo de desenvolvimento da leitura, uma vez que exige a tomada de perspectiva do outro (autor) e a percepção do texto enquanto objeto significativo e diferenciado do leitor. Capacidade esta que é aprimorada nas várias aproximações entre o leitor/autor via texto, em atividades significativas de leitura.

Contudo, quando se abandona a perspectiva de desenvolvimento e se admite a perspectiva de deficiência, então, é provável supor que a inabilidade para integrar o conhecimento prévio às informações textuais e gerar relações significativas entre as diversas informações disponíveis constitui-se como um fator caracterizador da dificuldade de compreensão das crianças participantes deste estudo.

Desta maneira, sugere-se que o problema de compreensão das mesmas está circunscrito na incapacidade de ativar as redes de conhecimento existentes na memória e/ou de usálas eficiente e apropriadamente durante a leitura de textos, fazendo-se crer que dificuldades desta natureza podem acarretar danos sobre as capacidades de integrar informações e de construir inferências. Hipótese esta que, também pode ser explicativa da não existência de diferenças entre os participantes em decorrência da variação da idade dos mesmos.

Outra hipótese que pode explicar a dificuldade dos participantes para integrar as informações do texto ao conhecimento prévio, diz respeito às condições e tempo de treinamento, visto que este ocorreu em uma única sessão, sendo a avaliação da compreensão de leitura realizada imediatamente após o mesmo.

No que diz respeito à eficácia do treinamento das estratégias de Tomar Notas e da Imagem Mental como possibilitador da emergência do conhecimento prévio do leitor e de sua integração a outros níveis de conhecimento, como, por exemplo, o lingüístico e o textual, nossos resultados demonstram um efeito limitador.

\section{Treinamento X Grupos Experimentais e Controle}

Verifica-se, no entanto, que o uso destas estratégias de auxílio à compreensão mostra-se positivamente efetivo para favorecer o surgimento de um novo estilo de leitura, caracterizado por uma maneira mais qualitativa e mais significativa das crianças lidarem com as informações do texto. Neste sentido, ao se observar o desempenho delas nos dois momentos do estudo, constata-se que, na primeira fase, toda a amostra revelou um perfil de leitura mais voltado para su- 
cesso sobre as questões literais do que sobre as inferenciais, com exceção das crianças do GE2 (Imagem Mental), que já nesta fase, exibiram um bom desempenho sobre essas últimas questões.

Este desempenho diferenciado do GE2 em relação às questões inferenciais, no momento da avaliação, pode ser atribuída a outros fatores, como por exemplo, a inteligência geral, a capacidade de memória, a capacidade de vocabulário, a capacidade de monitoramento, o conhecimento a respeito das várias estruturas de texto, que não foram controlados neste estudo, mas que podiam estar presentes nas crianças deste grupo de uma maneira mais marcante do que naquelas do GE1 (Tomar Notas) e do GC.

No entanto, os resultados obtidos na segunda fase deste estudo não parecem confirmar esta possibilidade, uma vez que não se constata, nesta fase, um progresso significativamente ascendente do GE2 em relação a si mesmo e aos outros dois grupos, no que se refere às questões inferenciais. Além disso, ao se observar a performance dos Grupos Experimentais e Controle, verifica-se que não houve diferenças significativas entre o GE1, o GE2 e o GC quanto às questões inferenciais, na primeira fase do estudo. Isto parece indicar que esses grupos estavam, no momento anterior ao treinamento, aproximados quanto ao desempenho apresentado sobre a atividade de compreensão de leitura.

Verifica-se, portanto, no momento do pós-teste, uma alteração no quadro do perfil inicial apresentado pelos grupos experimentais e controle, evidenciando-se uma diferenciação mais caracterizada entre eles. Deste modo, observa-se uma certa estabilidade na performance do GE2 (Imagem Mental) e uma mudança global no desempenho do GE1 (Tomar Notas), que se contrapõem ao desempenho cristalizado do GC (Controle), constatando-se, conseqüentemente, nos grupos experimentais, um modo novo e mais eficiente de lidarem com as informações do texto.

Esta mudança de estilo de leitura revelado pelo GE2 e, especialmente, pelo GE1 parece indicar que a releitura de um texto não é suficiente para garantir uma compreensão significativa e integrativa, como muitos poderiam supor, pois mesmo tendo a oportunidade de reler a história, na segunda fase do estudo, as crianças do GC continuaram a demonstrar um estilo de leitura voltado basicamente para a memorização das informações literais contidas no texto, utilizando-se, sobretudo, de estratégias associadas ao apelo à memória.

Como foi salientado no Método, a criança era solicitada, na segunda sessão, a ler e a responder às questões de uma história já conhecida. No entanto, é importante que se frise que Dias e cols. (1995) não evidenciaram uma melhora da performance dos participantes do GC, após a releitura da história que foi usada no primeiro momento do seu estudo, mas verificaram o progresso dos participantes pertencentes ao GE, que também releram a história, mas que, diferentemente do GC, receberam o treinamento para o uso da estratégia da Imagem Mental.

Ainda no que se refere ao desempenho apresentado pelo GE2 (Imagem Mental), pode-se dizer que mesmo exibindo um progresso mais sutil do que aquele demonstrado pelo GE1 (Tomar Notas), ele mostrou um estilo de leitura mais elaborado do que aquele revelado pelo GC, no segundo momento do estudo, confirmando, assim, a eficácia da estratégia da Imagem Mental para favorecer a reconstrução do significado do texto a partir da integração das informações e para possibilitar um melhor funcionamento da memória de trabalho; como já tinha sido observado nos estudos de Dias e cols. (1995) e Dias (1995), realizados com crianças brasileiras; e no estudo de Oakhill e Patel (1991), realizado com crianças inglesas.

Quanto ao GE1 (Tomar Notas), o salto qualitativo observado foi ainda mais expressivo, revelando um progresso global, marcado, especialmente, pelo avanço sobre as questões inferenciais. Este resultado parece evidenciar a estratégia de Tomar Notas como uma estratégia mais poderosa e mais eficaz do que a estratégia da Imagem Mental para favorecer a construção de inferências. Este efeito poderoso dessa estratégia parece estar associado ao fato do seu uso possibilitar um maior envolvimento do leitor com o texto escrito, favorecendo a reelaboração da informação a partir da própria experiência da escrita, que passa a funcionar como um instrumento de suporte para a recuperação da mensagem a ser lembrada.

Além disso, a possibilidade de escrever sobre o que foi lido, parece levar a criança a rever a sua compreensão do texto através da interpretação do que escreve, tendo ainda, a chance de conferir a sua reprodução com o que está escrito de forma literal no texto, no próprio momento da sua produção, podendo alterá-la, melhorá-la ou rejeitá-la através de várias releituras do seu texto e do texto original; tendo, por fim, a oportunidade de ler a sua produção para o adulto com quem estabelece uma relação.

\section{Treinamento X Tipo de Escola}

Nossos resultados demonstram que é possível ensinar à criança uma maneira mais significativa de abordar o objeto texto, levando-a, conseqüentemente, a desenvolver estratégias de processamento de informação mais eficientes e a superar as dificuldades de compreensão de leitura.

Os resultados intergrupos obtidos a partir da análise do desempenho dos grupos experimentais e controle, apontam o treinamento da Imagem Mental como o mais efetivo para possibilitar a promoção da habilidade de compreensão entre as crianças da escola pública. Quanto a este aspecto, nossos resultados confirmam aqueles encontrados por Dias e cols. (1995) no que diz respeito ao melhor aproveitamento do uso da Imagem Mental pelas populações das escolas municipal e estadual do que pela a da escola particular.

Constata-se, ainda, que entre os grupos experimentais e controle, pertencentes à escola pública estadual, o GE1 (Tomar Notas) foi o que mais evoluiu em relação a si mesmo, de um momento para o outro do estudo, levando-se a crer que o treinamento para o uso da estratégia de Tomar Notas pode se mostrar eficaz tanto quando ministrado a popula- 
ções de escola pública estadual, como quando ministrado a populações de escola particular.

Vê-se, portanto, a partir do conjunto dos resultados deste estudo, que é possível fazer da leitura um objeto de aprendizagem revestido de sentido e voltado para o seu principal objetivo: a compreensão. Verifica-se, ainda, que a superação de dificuldades de compreensão de texto pode ser alcançada através de um ensino de leitura fundamentado no ensino de estratégias de leitura que visem a construção conjunta e/ou individual de significados e que valorizem, além da decodificação, a integração de informações no texto, a construção de inferências, os conhecimentos lingüísticos e textuais, e a negociação entre o conhecimento prévio do leitor e as informações do texto, possibilitando, por sua vez, o contato do leitor não-habilidoso com os procedimentos utilizados pelo leitor proficiente.

Neste sentido, a instrução para o uso das estratégias de Tomar Notas e da Imagem Mental, constitui-se como um instrumento de efeito positivo para promover a habilidade de compreensão de leitura, uma vez que possibilita a participação ativa do leitor com o texto, favorecendo a integração das informações nele contidas e a construção de inferências, como faz o leitor habilidoso. Deste modo, de acordo com as idéias difundidas nos Parâmetros Curriculares Nacionais da Língua Portuguesa, defende-se que é necessário que se "aprenda a ler, lendo", que se ensine a ler oferecendo práticas de leitura que privilegiem a reflexão, que visem, como nas práticas sociais, a realização de objetivos pessoais e que estimulem o desenvolvimento de estratégias e de procedimentos de leitura que se assemelhem àqueles utilizados pelo leitor proficiente e que objetivem, acima de tudo, a construção de sentido.

Para isto, é importante que o professor de leitura fundamente a sua prática pedagógica e didática no conhecimento a respeito dos processos envolvidos na leitura e que, a partir deste conhecimento, seja capaz de entender que o conhecimento prévio do aluno-leitor é um pré-requisito fundamental e indispensável para que a compreensão de texto estabeleça-se, pois, como afirma Kleiman (1997), sem o engajamento do conhecimento prévio do leitor não há compreensão.

Porém, para que a escola ensine a criança a superar as suas dificuldades de compreensão e a ler proficientemente, faz-se necessário, ainda, que ela abandone as antigas concepções de leitura cristalizadas ao longo do tempo, substituindo a idéia de leitura como decodificação e a idéia do mito da única interpretação válida pela concepção da leitura ligada à construção de significados múltiplos e, portanto, como atividade social, polissêmica e individual.

\section{Referências}

Brandão, A.C.P. (1994). Produção e compreensão de histórias. Dissertação de Mestrado. Universidade Federal de Pernambuco, Recife, PE.

Dias, M.G.B.B. (1995). Melhorando a compreensão de leitura: uma estratégia de fácil aplicação. Trabalho apresentado na mesa redonda "As Contribuições das Pesquisas em Psicologia Para a Educação" e publicado completo nos Anais da $47^{a}$ Reunião Anual da SBPC, São Paulo, 9 a 14 de julho: 261-262.

Dias, M.G.B.B, Morais, E.P.M \& Oliveira, M.C.N.P (1995). Dificuldades na compreensão de textos: uma tentativa de remediação. Arquivos Brasileiros de Psicologia, 47(4), 13-24.

Garton, A. \& Pratt, C. (1989). Learning to be literate: The development of spoken and written language. Oxford: Blackwell.

Kleiman, A. (1997). Texto e leitor: aspectos cognitivos da leitura. ( $5^{a}$ edição). Campinas, SP: Pontes.

Levin, J.R. (1973). Inducing comprehension in poor readers: A test of recent mode. Journal of Educational Psychology, 65(1), 19-24.

Levin, J.R. (1981). On functions of pictures in prose. Em F.J. Pirozzolo \& M. C.Wittrock (Orgs.), Neuropsychological and cognitive processes in Reading (pp. 64-86). London: Academic Press.

Lins e Silva, M.E. (1994). O desenvolvimento da escrita de histórias. Dissertação de Mestrado. Universidade Federal de Pernambuco, Recife, PE.

Oakhill, J., Cain, K. \& Yuill, N. (1997). Individual diferences in children's comprehension skill: Towards and integrated model. Em C. Hulme \& M. Joshi (Orgs.) Reading and spelling: Development and desorder (pp. 82-104). Merhwarh, N.J.: Erlbaum Associates.

Oakhill, J. \& Garnham, A. (Orgs.). (1988). Becoming a skiller reader. Oxford: Blackwell.

Oakhill, J. \& Patel, S. (1991). Can imagery training help children who have comprehension problems? Journal Research in Reading, 14, 106-115.

Oakhill, J. \&.Yuill, N. (1996). Higher order factors in comprehension disability: Processes and remediation. Em C. Cornoldi \& J.V. Oakhill (Orgs.), Reading comprehension difficultes: Process and remediation (pp. 69-92). Hillsdale, N.J: Lawrence Erlbaum.

Pressley, G.M. (1976). Mental imagery helps eight-years olds remember what they read? Journal of Educational Psychology, $68,355-359$.

Spinillo, A.G. (1991). O efeito da representação pictográfica na produção de narrativas. Psicologia: Teoria e Pesquisa, 7, 311326.

Spinillo, G. \& Pinto, G. (1994). Children's narratives under different conditions: A comparative study. British Journal of Developmental Psychology, 12, 177-193.

Terzi, S.B. (1995). A construção da leitura: uma experiência com crianças de meios iletrados. Campinas, SP: Pontes; Editora da UNICAMP.

Trabasso, T. \& Nicholas, D.W. (1980). Memory and inferences in the comprehension of narratives. Em F. Wiltening, J. Becker \& T. Trabasso (Orgs.). Information integration by children (pp. 215-242). Cambridge, Mass.: Erlbaum.

Recebido em 11.01.2001

Primeira decisão editorial em 14.12.2001

Versão final em 14.04.2002

Aceito em 16.04.2002 


\section{ANEXOA \\ Histórias e Questões utilizadas}

\section{Primeira História}

O maior sonho de Maria era poder voar como os passarinhos.

Certo dia, ela encontrou no jardim uma pomba com a asa machucada.

Maria cuidou da pobre ave até ela ficar boa. A pombinha, que na verdade era uma fada, disse:

Você mostrou que é uma boa menina e eu vou realizar seu desejo.

E falou as palavras mágicas:

Camurú camará, que ela comece a voar.

Maria ficou com o corpo bem leve e foi subindo devagar. Voou bastante, apostou corrida com os passarinhos e achou engraçado ver como as pessoas lá embaixo ficaram parecendo formiguinhas. De repente, ela sentiu que estava descendo. O encantamento havia acabado.

\section{Questões - Primeira História}

1) Qual era o sonho de Maria?

2) O que Maria encontrou no jardim?

3) Em quem a pomba se transformou?

4) Por que a pomba não podia voar?

5) Qual o sentimento de Maria quando ela estava voando?

6) Por que as pessoas ficaram parecendo formiguinhas?

\section{Segunda História}

Em um planeta distante, muito diferente da terra, moravam seres esquisitos que andavam com as mãos no chão, tinham os corpos cobertos de penas coloridas e olhos salientes presos aos pés.

Neste lugar morava Quipu, um habitante que se sentia muito infeliz por ser diferente dos outros. O seu maior desejo era que todas as pessoas do seu planeta fossem iguais a ele.

Certo dia, um grupo de crianças construiu uma espaçonave e saiu da terra em direção ao planeta Xanci, onde vivia o habitante infeliz. Quando o encontraram, Quipu ficou muito contente por finalmente conhecer pessoas semelhantes a ele e resolveu juntar-se ao grupo indo morar na terra, desistindo de tentar modificar as pessoas do seu planeta.

\section{Questões - Segunda História ${ }^{2}$}

1) Qual era o desejo de Quipu?

2) Qual era o problema de Quipu?

3) Quem construiu a espaçonave ?

4) Como Quipu resolveu seu problema?

5) Como ele viajou para a terra?

6) Com quem Quipu parece?

\section{Terceira História}

Paulo, Rogério e Sandro são os únicos netos da vovó Lami que mora numa fazenda na cidade de Sadesa.

Nas férias da escola, eles decidiram ir para a fazenda. Chegando lá, perceberam que os moradores da cidade estavam demasiadamente assustados com uma luz muito intensa e brilhante, que mais parecia mágica, vinda da montanha encantada.

Os três meninos, corajosos que eram, decidiram investigar o mistério da luz mágica, apesar da avó ter recomendado que eles não se aproximassem da montanha.

Sandro o mais velho, comandou a expedição. Seguiram por uma velha trilha sinuosa e bastante acidentada que fora construída por turistas. Logo na metade da trilha depararam-se com barracas queimadas, restos de comida, cinzas de fogueira que pareciam destroços de um acampamento abandonado. Dentre os destroços havia, também, um imenso espelho quebrado que brilhava muito, refletindo a luz do sol.

Eles perceberam, então, que a montanha não era encantada, nem tampouco a luz era mágica, tranqüilizando os moradores da cidade.

\section{Questões - Terceira História ${ }^{3}$}

1) Quem mora na fazenda?

2) Por que os moradores da cidade de Sadesa estavam assustados?

3) Quem foi até a montanha investigar o mistério?

4) Onde moravam os netos da vovó Lami?

5) Quem deixou restos de comida e cinzas de fogueira no caminha que leva à montanha?

6) Qual era o mistério da luz encantada?

1 As três primeiras questões foram consideradas literais e as três últimas, inferenciais.

2 As três primeiras questões foram consideradas literais e as três últimas, inferenciais.

3 As três primeiras questões foram consideradas literais e as três últimas, inferenciais. 


\section{ANEXO B}

\section{História e Questões utilizadas}

\section{Para o treinamento das estratégias de compreensão}

Era uma vez uma flor que morava num quintal cheio de árvores grandes. A flor vivia muito triste pois não havia ninguém com quem pudesse conversar. As árvores grandes não gostavam dela e nunca a convidavam para brincar.

Um dia, a flor viu um passarinho e resolveu conversar com ele. Ela foi logo dizendo que estava muito triste e sozinha.

- Por que você está triste? Perguntou o passarinho.

- Aqui fico muito sozinha, disse a flor. Não tenho amigos. Você poderia ajudar?

- Não se preocupe, respondeu o passarinho, tenho uma idéia, para acabar com sua tristeza. E lá foi ele voando rápido para um jardim vizinho.

Neste jardim o passarinho apanhou com o bico varias sementes de flores. À noite, voltou para o quintal onde a florzinha morava e enquanto ela dormia, plantou as sementes na terra.

Naquela noite, choveu muito. Ao amanhecer, a flor teve uma grande surpresa. O quintal parecia um lindo jardim!

Desde então, a flor viveu muito feliz, pois agora tinha muitos amigos para conversar.

\section{Questões - História Adicional}

1) Quem morava num quintal cheio de árvores grandes?

2) Qual era o problema da flor?

3) Com quem a flor se encontrou, certo dia?

4) Como a flor se sentia?

5) O quê a flor mais queria?

6) O que o passarinho fez para resolver o problema da flor?

7) Por que as sementes cresceram tão rápido?

8) Qual a surpresa que a flor teve ao acordar?

9) Por que a flor passou a viver feliz?

5 As três primeiras questões foram consideradas literais e as demais, inferenciais. 